
\title{
R Reserarch Suare \\ Design and Optimization of an Electric Car Chassis and Body using Structural Analysis and CFD
}

Mohammed Aiyan ( $\square$ aiyankhan712@gmail.com )

BMSIT: BMS Institute of Technology https://orcid.org/0000-0003-3587-7315

\section{Sumanth Sagar}

BMS Institute of Technology

\section{Sanjay Raghav S}

BMS Institute of Technology https://orcid.org/0000-0002-5853-9506

\section{Research Article}

Keywords: Electric Car, Finite Element Analysis, Computational Fluid Dynamics, Composite Materials

Posted Date: June 1st, 2021

DOl: https://doi.org/10.21203/rs.3.rs-575396/v1

License: (1) This work is licensed under a Creative Commons Attribution 4.0 International License. Read Full License 


\section{Title: "Design and Optimization of an Electric Car Chassis and Body using Structural Analysis and CFD"}

Authors:

Mohammad Aiyan

BMS Institute of Technology \& Mgmt., Mechanical Engineering, Bangalore, India ORCID: 0000-0003-3587-7315

S Sumanth Sagar

BMS Institute of Technology \& Mgmt., Mechanical Engineering, Bangalore, India ORCID: 0000-0001-7967-7548

Sanjay Raghav S (Corresponding Author)

BMS Institute of Technology \& Mgmt., Mechanical Engineering, Bangalore, India Email: sanjayraghav99@gmail.com

ORCID: 0000-0002-5853-9506 


\section{DECLARATION}

Funding (Non-Applicable)

Conflicts of Interest/Competing Interest - On behalf of all authors, the corresponding author states that there is no conflict of interest.

Availability of Data and Material (Applicable)

Code Availability (Non-Applicable)

Ethics Approval (Non-Applicable)

Consent to Participate (Applicable)

Consent for Publication (Applicable) 


\title{
Design and Optimization of an Electric Car Chassis and Body using Structural Analysis and CFD
}

\author{
Mohammad Aiyan, S Sumanth Sagar, Sanjay Raghav S (Corresponding Author)
}

\begin{abstract}
The transition from traditional gasoline-powered automobiles to electric vehicles (EVs) has taken time, two major challenges of engine- powered vehicles are greenhouse gas emissions and fuel economy. Electric cars require less maintenance. A lot of money can be saved while also helping the environment. In today's world, working with lightweight materials have emerged as a key area for improvement in the automotive industry. The most efficient method for increasing power output is to reduce the weight of vehicle components. Composite materials have benefited greatly from research and development because they are stronger, more recyclable, and easier to integrate into vehicles. The primary goal of this research is to design the body and chassis frame of a two-seater electric car. A CFD analysis was performed to determine the drag coefficient of the body along with structural analysis to obtain the frontal impact and torsional rigidity of the chassis to develop an effective electric car design. The design was carried out with the help of CATIA V5 software, while the analysis was performed using ANSYS 19.2. A comparative analysis of the chassis was undertaken by incorporating three different materials namely, traditional steel i.e., Stainless Steel 304L, Aluminium Alloy 7075-T6, T300 Carbon Fibre composite. The energy efficiency of the car for the three materials are also computed.
\end{abstract}

Keywords- Electric Car, Finite Element Analysis, Computational Fluid Dynamics, Composite Materials

\section{INTRODUCTION}

One of the main contributors to the greenhouse effect is the burning of fossil fuels for transportation and heating. The transport sector is currently the main consumer of fossil fuels. Hence, car manufacturers are starting to implement a more sustainable approach when developing vehicles with the focus on electric vehicles. Electric cars are emerging as a promising solution for the near future. Being battery powered, these vehicles do not perform as well as the conventional automobiles, and hence they need to be optimized effectively on all other fronts to derive maximum performance from electric power. The two most effective approaches to do this would be to improve the vehicle's aerodynamics and make it as light as feasible. At highway speeds, an electric vehicle's air resistance can reach up to $48 \%$ of its total driving resistance. (Tamer Nabil*, 2020) Aerodynamic design of cars is crucial as it directly affects the fuel economy and stability in motion. A virtual wind tunnel can be developed with the help of CFD analysis in order to obtain the drag force on the vehicle body. A streamlined car has less drag, whereas a boxy vehicle, such as a bus, has a high aerodynamic drag; thus, the goal of this research is to develop a practically streamlined body to maximise the performance of the electric car.

The second aspect of this project is to design a chassis for the electric car. In general, achieving lightweight and rigid automobile structures plays a critical role in maximising electric car efficiency. Without a doubt, the chassis is one of the most crucial components of the construction. As a result, it must be constructed in such a way that it reduces weight while improving total vehicle performance. In order to meet the strength, low manufacturing cost, and aesthetic standards of common lightweight urban cars, space frame structures are frequently used (R.K. Kawade, 2017). A space frame chassis was chosen for the study as it is rigid, lightweight, cost effective and simple to manufacture. On the other hand, chassis stiffness requirements make any weight reduction difficult and costly. For the development of both high-performance and costeffective road vehicles, the problem of finding the best compromise between chassis stiffness, weight, and cost is critical. (Luiz CarlosGertz, 2015) The structural components of the chassis frame, such as cross members, must be strategically located to reduce frame twist and minimise local deflections of suspension mounting brackets. Chassis stiffness is a direct factor of torsional rigidity. Increasing the torsional rigidity of a vehicle improves ride comfort quality by allowing the suspension to work more efficiently.

The torsional rigidity of a vehicle's chassis can be defined as "how much a frame will flex as it is loaded when one front wheel is up and one front wheel is down while the rear of the car is held level" in simple terms. Having a good torsional rigidity results in good handling. The task of designing a chassis is to improve the torsional stiffness without compromising the its weight. One way of doing this is to incorporate lightweight materials into the chassis. The rising popularity of composite materials such as Fibre Reinforced Plastics (FRPs) and Metal Matrix Composites (MMCs) has made it possible for these materials to find applications in the automotive industry. Carbon fibres are an excellent choice of material when it comes to chassis building due to their high strength, lightweight, thermal resistance and flexibility. (H Ahmad, 2020) In this study, a comparison is made between carbon fibre chassis, the traditionally used stainless steel and newly introduced aluminium alloy. 


\section{MODELLING}

\subsection{Electric Car Body}

The body of the car is designed in CATIA V5 software. For economical, city friendly purposes, a two-seater hatchback design is chosen. Inspired by the British Leyland Mini 1000 Mk. 4, this design has a length of $3150 \mathrm{~mm}$, height of $1737 \mathrm{~mm}$ and a width of $1400 \mathrm{~mm}$. The wheelbase of the car is $1810 \mathrm{~mm}$ with a ground clearance of $200 \mathrm{~mm}$. The objective is to develop a two-seater car that is ergonomic, roomy, and rides well. The low ground clearance provides better handling as less air will pass under the car. To add to this, a spoiler with standard specifications is designed to assist in aerodynamics. (Fig I)

TABLE I

DIMENSIONS OF ELECTRIC CAR

\begin{tabular}{lc}
\hline & Dimensions \\
\hline Length & $3150 \mathrm{~mm}$ \\
Width & $1400 \mathrm{~mm}$ \\
Height & $1737 \mathrm{~mm}$ \\
Wheelbase & $1400 \mathrm{~mm}$ \\
\hline
\end{tabular}

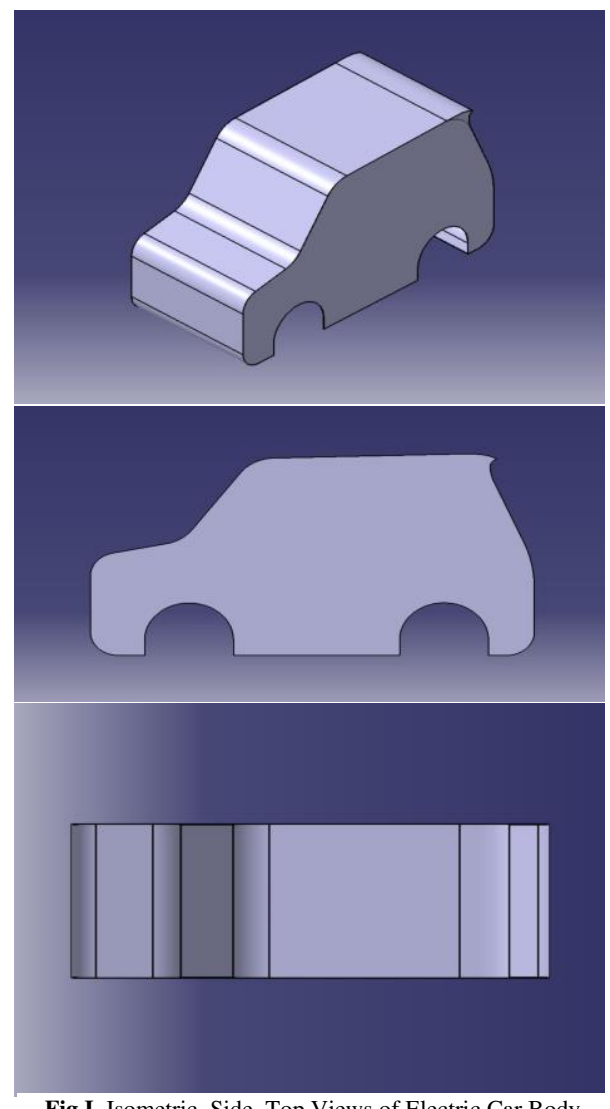

Fig I. Isometric, Side, Top Views of Electric Car Body

\subsection{Chassis}

Chassis modelling was performed with the help of Wireframe and Surface design in CATIA V5 software. A space frame chassis was chosen for this design keeping (R.K. Kawade, 2017) in mind with our aim to design a cost-effective and electric car. In this regard a new chassis is designed as per the dimensions of the body with tubular beams of circular cross section with $25 \mathrm{~mm}$ diameter and a thickness of $2 \mathrm{~mm}$. The design is carried out taking ergonomics and stiffness into consideration. (Fig II) (Fig III)

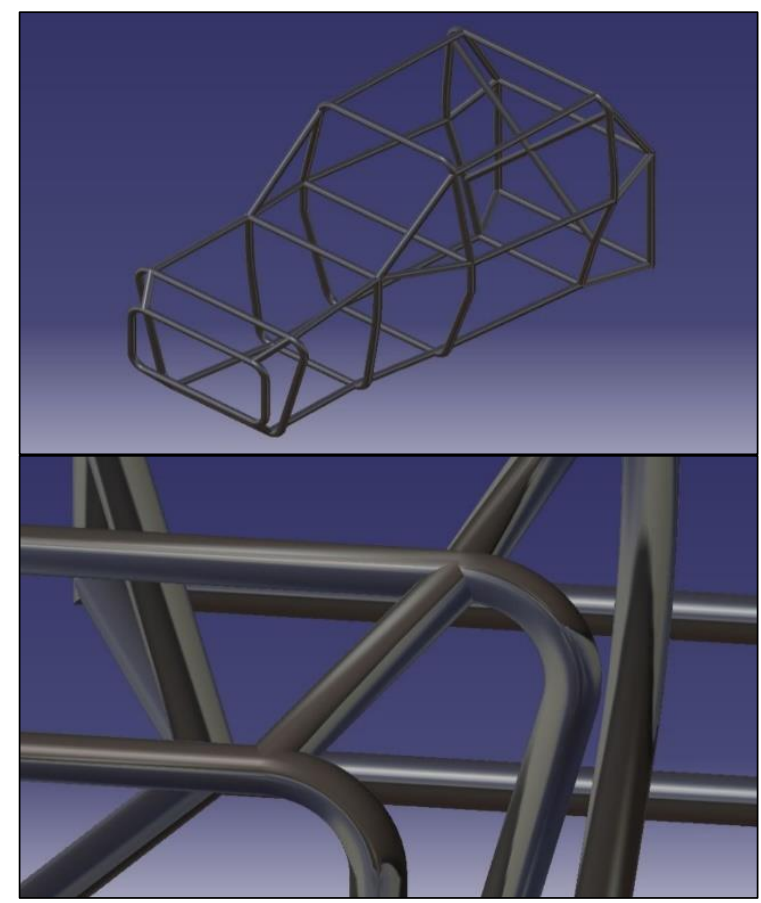

Fig II. Model of Frame; Circular Cross Section of Tubular Space frame



Fig III. Electric Car Body on Space Frame

\section{SIMULATION AND ANALYSIS}

\subsection{Analysis of Electric Car Body: Computational Fluid Dynamics}

The body of the electric car is first imported from the CATIA V5 Software into the ANSYS 19.2 software and the CFD simulation tool FLUENT is used, after which an enclosure is created surrounding the car body to simulate the Wind tunnel, 
the dimensions are $12 \mathrm{~m}, 8 \mathrm{~m}$ and $4.5 \mathrm{~m}$ in the $\mathrm{x}, \mathrm{y}$ and $\mathrm{z}$ direction respectively. The inlet of the wind tunnel was placed at half car-length in front of the car and the outlet was 2 times the car-length from behind the car to capture the flow at the wake downstream of the car. (Louis Cattafesta, 2010)

Following this a volume mesh of $0.8 \mathrm{~m}$ element size and High smoothness is done with an incorporation of 10 layers of inflation. In aerodynamic simulations it is recommended to refine the cells of the mesh in order to determine any unsteady or turbulent fluid phenomena caused by the separation of the boundary layer from the car body. The number of nodes and elements being 82506 and 389924 respectively.

\subsubsection{Boundary Conditions}

The Boundary conditions are applied onto the meshing as stated above. The wind tunnel-car body setup is then specified to have a velocity inlet, a pressure outlet, the car body and side-walls which are treated as non-Slip walls to simulate the wind tunnel conditions. The analysis is carried at three different inlet velocities of $40 \mathrm{kmph}, 60 \mathrm{kmph}$ and $80 \mathrm{kmph}$ and outlet pressure set at zero pascal for 200 iterations for the model so as to enable a thorough comparative study of its performance at the real-world conditions that the car body will be subjected to.

Turbulence Modelling: The Mach number is below 0.3 therefore the flow is incompressible and steady in nature. The Reynolds Averaged Navier-Stokes RANS equations are solved to simulate the incompressible turbulent flow and the energy equation is not considered as there are no temperature conditions. K-Epsilon $(\mathrm{k}-\varepsilon)$ realizable is taken as the turbulence model as it is ideal for external geometry with flow separation. Pressure velocity coupling is used to calculate the pressure field for which the COUPLE algorithm is implemented.

The car body frame is subjected to $40 \mathrm{kmph}, 60 \mathrm{kmph}$ and $80 \mathrm{kmph}$ inlet velocity speeds so as to simulate the conditions it will be subjected to while in Real-World use. To verify this the Drag coefficient and Drag force values for the car were calculated in the ANSYS FLUENT software. These parameters help in determining if the car body can run at the mentioned speeds without any disruptions. The values are tabulated. (TABLE IV)

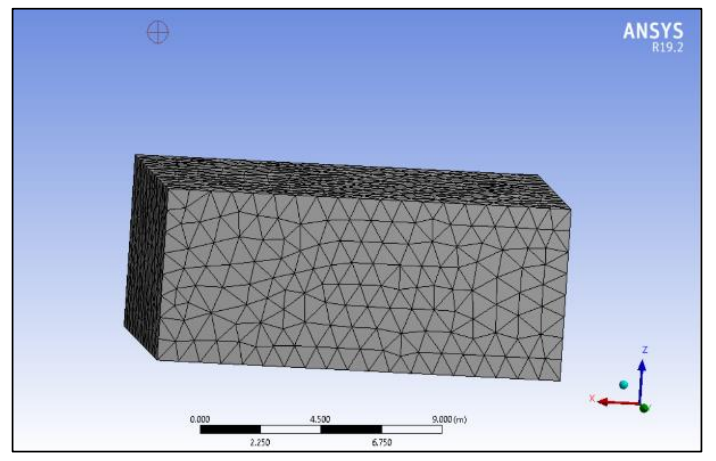

Fig IV. Meshing of Virtual Wind Tunnel

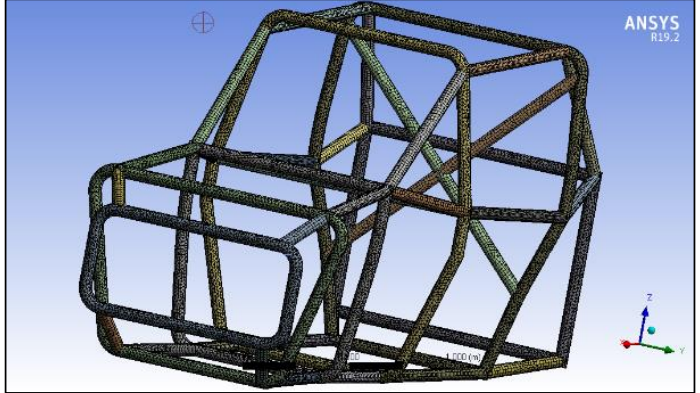

Fig V. Meshing of Chassis Frame

\subsection{Analysis of Electric Car Chassis: Structural Analysis}

\subsubsection{Material Selection}

The main parameters to be satisfied by the materials used for the chassis of an electric car is that it should be lightweight so as to reduce the load on the car battery, it should have a high yield strength so as to be rigid, safe to be used for passengers and it should be economical to manufacture. An extensive study was carried out following which Aluminium Alloy 7075-T6 and T300 which is a carbon fibre composite are selected as the potential materials. Carbon fibre usually combined with other materials to form a strong composite. When impregnated with plastic resin such as epoxy and baked, it forms carbon-fibre-reinforced polymer which has high strength-to-weight ratio, and is extremely rigid. ( $\mathrm{H}$ Ahmad, 2020)

A comparative analysis of these materials is carried out along with the traditionally used Steel 304L alloy. The comparative analysis allows us to identify the most efficient material for use. The mass of the chassis for each material is listed below along with the percentage reduction in weight. (

TABLE VI) The weight reduction in chassis plays an important role as it affects the overall performance of the vehicle.

\section{A. Aluminium 7075-T651:}

Aluminium 7075-T651 is a commonly used 7-series Aluminium alloy. Among the other Aluminium alloys, it is 
found to have the best strength and is highly suitable for highstrength applications. The main elements in the alloy are zinc and magnesium and a small percent of copper. This alloy is now beginning to be widely used in the automotive and aviation industries.

\section{B. T300 Carbon Fibre Composite:}

T300 Carbon Fibre is a Fibre reinforced plastic (FRP) and there is an increased use of fibre reinforced plastics (FRPs) over the traditional materials due to their better properties over other engineering materials. The properties include high strength to weight ratio, excellent corrosion, thermal resistance and high fracture toughness. They are highly suitable for car chassis due their extreme light weight and high strength capabilities. (H Ahmad, 2020)

The properties of the 3 materials used for the chassis are shown in (TABLE II).

TABLE II

MATERIAL PROPERTIES

\begin{tabular}{llll}
\hline Properties & $\begin{array}{l}\text { Steel } \\
304 \mathrm{~L}\end{array}$ & $\begin{array}{l}\text { AA 7075- } \\
\text { T6 }\end{array}$ & $\begin{array}{l}\text { T300/Carbon } \\
\text { Fibre } \\
\text { composite }\end{array}$ \\
\hline $\begin{array}{l}\text { Young's modulus } \\
\text { (GPa) }\end{array}$ & 193 & 70 & 57 \\
$\begin{array}{l}\text { Ultimate Strength } \\
(\mathrm{MPa})\end{array}$ & 564 & 580 & 570 \\
$\begin{array}{l}\text { Yield Strength (MPa) } \\
\text { Shear Modulus }\end{array}$ & 210 & 460 & 530 \\
$\begin{array}{l}\text { (GPa) } \\
\begin{array}{l}\text { Poisson's Ratio } \\
\text { Density (kg/m³) }\end{array}\end{array}$ & 75 & 26 & 3 \\
\hline
\end{tabular}

\subsubsection{Structural Analysis}

The frame is subjected to structural analysis to determine its behaviour at the industry conditions and to evaluate if the frame can withstand these conditions without fracturing. The model is designed in CATIA V5 software first and is then imported into ANSYS 19.2 software package. The materials are first created in the Engineering Sources as they are not predefined and then they are assigned to the model after which the structural analysis is performed for each material.

Meshing has to be done to the entire body car chassis and a meshing plan is devised wherein the element size chosen is $10 \mathrm{~mm}$ and a volume mesh is provided. This allows us to perform a highly accurate analysis. The number nodes and elements are 306586 and 194641 respectively and meshing image is shown. (Fig V)

\subsubsection{Torsional Analysis}

Design of a strong structure is important but is still inefficient if the chassis has insufficient rigidity which is a crucial parameter. The analysis of torsional rigidity is the most essential test to be conducted as it determines not only the comfort quality of the car but also the overall "Torsional stiffness" which demonstrates the vehicle behaviour at sharp turns and overall balance of the vehicle taking into consideration passenger safety. (Steven Tebby, 2011)

Bending Stiffness is another parameter which is determined by the acceptable limit deflection to make it possible to open the doors. This is required essentially when accelerating and braking. If the torsional stiffness of the chassis is adequate, the vehicle will not have problems of bending stiffness. (Luiz CarlosGertz, 2015) Along with this Frontal impact Tests of the chassis is conducted to evaluate the passenger safety in accidental situations. The impact forces simulated are $10,000 \mathrm{~N}$ and $20,000 \mathrm{~N}$ so as to verify the chassis structure strength at extremely high impacts. In general, torsional analysis is used to determine the relative stiffness between different types of chassis. Typically, a comparison between the torsional rigidity and the weight of the structure is made, to evaluate the efficiency. Therefore, Torsional rigidity and frontal impact test are sufficient to verify the structural integrity of the chassis.

\section{Torsional Rigidity}

The higher the values of torsional rigidity the more stable the vehicle is as low resistance to torsion leads to imbalance in curve-turning and causes instability, which can lead to accidents. This is extensively studied by several authors using both simulation and experimental analysis.

Firstly, the rear suspension of the car is applied with fixed supports to simulate car movement in turns where the rear wheels provide movement in uniaxial direction. The Front suspension of the left wheel is applied with loads equal to the weight of the entire car body in the downward direction following which the same forces are applied on the right side of the front suspension in the upward direction. An acceleration of $80 \mathrm{kmph}$ is provided to the entire chassis and standard earth gravity is applied. These conditions simulate the movement of the car along a turn at its maximum running speed and are applied for all the 3 different materials.

\section{Frontal Impact}

The front wheel suspensions and rear wheel suspensions are provided with fixed loads, following which forces of $10,000 \mathrm{~N}$ and $20,000 \mathrm{~N}$ are applied in the negative $\mathrm{x}$-direction. The forces applied are high so as to test the structural strength of the chassis to validate its safety for passengers. The conditions are applied for all the 3 different materials.

\subsubsection{Loading conditions}

Torsional rigidity: 




Frontal Impact Test:

$\begin{aligned} \text { i. } & \text { Case } 1=10,000 \mathrm{~N}(-\mathrm{X} \text { direction }) \\ \text { ii. } & \text { Case } 2=20,000 \mathrm{~N}(-\mathrm{X} \text { direction })\end{aligned}$

\subsection{Calculations}

a. Torsional Stiffness $\quad K=\frac{T}{\varphi}$

$\mathrm{K}$ is the torsional stiffness ( $\mathrm{Nm} /$ degree)

$\mathrm{T}$ is Torque applied to the front of the chassis (Nm) $\varphi$ Is the Torsion angle (degree)

b. Angle of Torsion $\quad \varphi=\sin ^{-1} \frac{2 D}{L}$

$\mathrm{D}$ is the vertical deflection of point of load application (m)

$\mathrm{L}$ is the distance between the applied loads (m)

c. Total Resisting Force $(N)=$ Air Drag Force $(N)+$ Tire Drag Force $(N)$

Tire Drag Force $(N)=$ Total Mass of $\operatorname{Car}(N) * C_{r}$

Assuming Coefficient of rolling friction $\mathrm{C}_{\mathrm{r}}=0.015$

d. Horse Power

$h p=\frac{\text { Force } \times \text { Speed }}{550}$

1 horsepower $=745.5 \mathrm{~W}$

\section{RESULTS AND DISCUSSION}

\subsection{Computational Fluid Dynamics Analysis on Car Body}

The simulations are run at the set inlet velocities of 40,60 and $80 \mathrm{kmph}$ at zero yaw angle to maintain the linear flow of air. The inlet velocities taken are taken so as to simulate the actual working velocity which the body of the car will be subjected to while in use. The residuals were achieved after 200 iterations for Car model and they remained constant as the iteration proceeded. The value of drag coefficient $\left(\mathrm{C}_{\mathrm{d}}\right)$ is found to be $0.348,0.347$ and 0.346 for 40,60 and $80 \mathrm{kmph}$ respectively with a drag force of 64.07, 143.659 and $254.701 \mathrm{~N}$ for the said inlet velocities respectively. (Fig VIII)
It is observed that a significant amount of pressure accumulation typically occurs at the front end of car bodies due to their box-like design which contributes in causing a separation between air and car body surface, which contributes to its high drag-coefficient. Also, the drag force at the rear end of the car body is also found to be high due to the non-tapering or linear design which causes vacuum creation at the rear end of the car surface causing increased pulling force called Drag Force. To counter these issues, firstly the front end is extended further and the windshield is inclined at an angle $\left({ }^{\circ}\right)$ to allow for an overall tapering surface for the air to have a steady and swift linear flow over the car surface. The corners of the front and side profile of the car are rounded to reduce air pressure due to accumulation on its surface. The car roof is modified from a simple straight profile to a linear tapering profile which tapers up from the front to the rear end of the body. This provides the airflow to steadily flow over the surface of the car body without accumulation. Finally, a spoiler was added to the top rear end of the car which is in geometrical relation with the car body which allows the air to flow over and prevents it from dropping down and creating a vacuum around that area. This helps in reducing the drag force created on the car.

The drag coefficient and drag force values are within the standard range and are ideal for use in passenger car as the aerodynamic inputs in design help improve performance as compared to other designs currently used. At the front end of the car body, the stagnation of air causes a positive pressure coefficient value, in this stagnation area, airspeed increases due to the windshield inclination angle which results in decrease in pressure coefficient value. At the edges, the pressure coefficient value reduces significantly as the airspeed is maximum here. After which air travels along the top surface while remaining attached to the surface i.e., No separation occurs due to its upwards tapering profile which causes the pressure coefficient curve to become positive and it remains constant. The difference between frontal and rear pressure is reduced significantly thereby resulting in a lower drag force at the rear end of the car body and lesser surface pressure acting on the car body as shown in the figure. (Fig VI , Error! Reference source not found.)

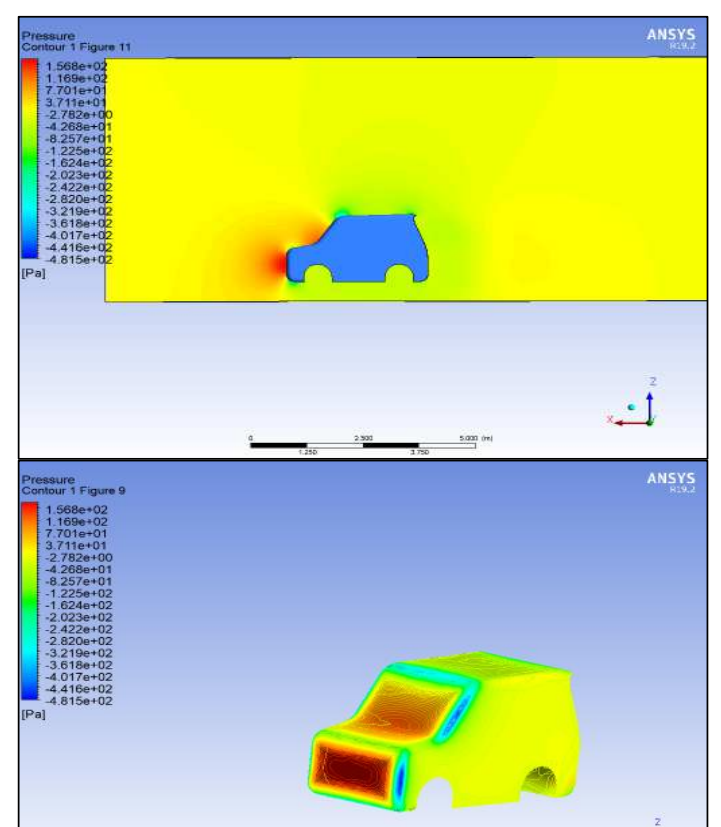


Fig VI. Pressure Contour of Electric Car Body

TABLE III

TORSIONAL RIGIDITY FOR DIFFERENT MATERIALS

\begin{tabular}{llllll}
\hline Material & $\begin{array}{l}\text { Acceleration } \\
(\mathrm{kmph})\end{array}$ & $\begin{array}{l}\text { Total Deformation } \\
(\mathrm{mm})\end{array}$ & $\begin{array}{l}\text { Equivalent Von-Mises } \\
\text { Stress (MPa) }\end{array}$ & $\begin{array}{l}\text { Vertical direction } \\
\text { deformation }(\mathrm{mm})\end{array}$ & $\begin{array}{l}\text { Torsional Stiffness } \\
(\mathrm{kNm} / \mathrm{degree})\end{array}$ \\
\hline Steel 304L & 80 & 0.765 & 34.16 & 0.393 & 451.965 \\
AA 7075 & 80 & 0.999 & 25.67 & 0.117 & 94.573 \\
T300/Epoxy & 80 & 0.881 & 26.51 & 0.498 & 31.885 \\
\hline
\end{tabular}

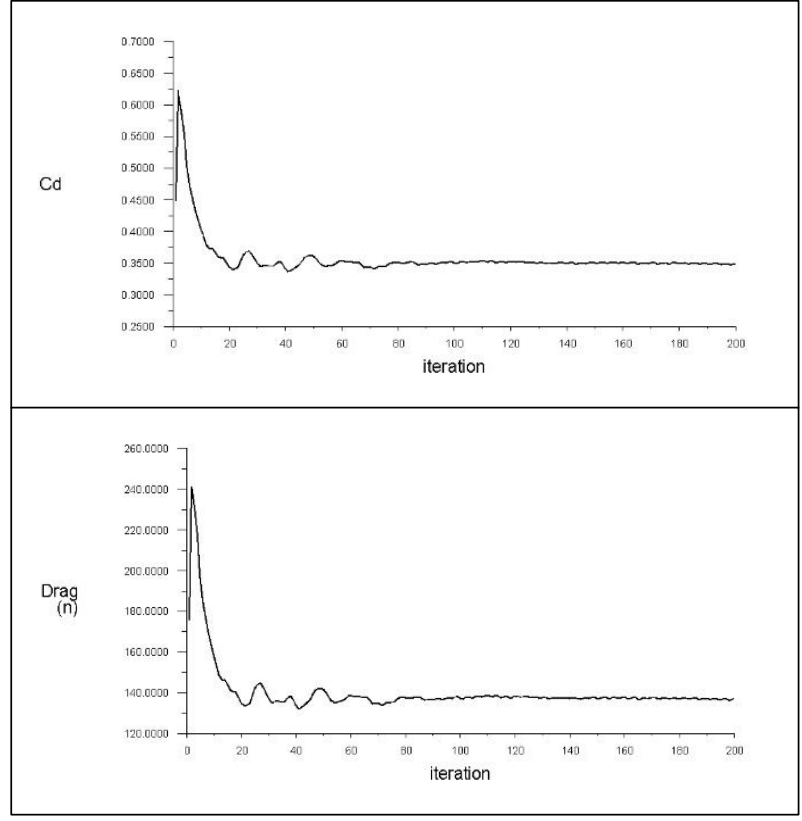

Fig VII. Drag Force and $\mathrm{C}_{\mathrm{d}}$ curves

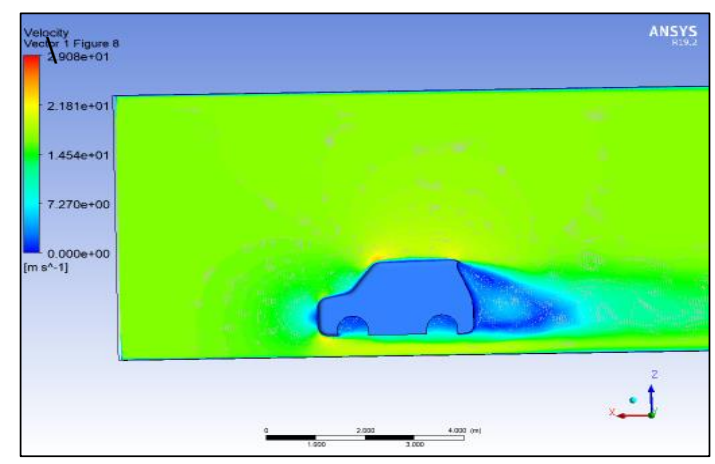

Fig VIII. Velocity Contour from CFD Analysis

TABLE IV
CFD RESULTS FOR ELECTRIC CAR BODY

\begin{tabular}{lll}
\hline $\begin{array}{l}\text { Inlet Velocity } \\
(\mathrm{Kmph})\end{array}$ & $\begin{array}{l}\text { Drag Coefficient } \\
\mathrm{C}_{\mathrm{d}}\end{array}$ & $\begin{array}{l}\text { Drag Force } \\
(\mathrm{N})\end{array}$ \\
\hline 40 & 0.3482 & 64.070 \\
60 & 0.3470 & 143.659 \\
80 & 0.3460 & 254.701 \\
\hline
\end{tabular}

TABLE V

FRONTAL IMPACT ANALYSIS FOR DIFFERENT MATERIALS

\begin{tabular}{llll}
\hline Material & $\begin{array}{l}\text { Force } \\
(\mathrm{kN})\end{array}$ & $\begin{array}{l}\text { Total } \\
\text { deformation } \\
(\mathrm{mm})\end{array}$ & $\begin{array}{l}\text { Equivalent von- } \\
\text { Mises stress }(\mathrm{MPa})\end{array}$ \\
\hline Steel & 10 & 0.139 & 31.148 \\
304L & 20 & 0.279 & 62.297 \\
& & & 31.644 \\
AA & 10 & 0.376 & 63.288 \\
7075 & 20 & 0.753 & \\
& & & 29.695 \\
T300 & 10 & 0.465 & 59.388 \\
\hline
\end{tabular}

\subsection{Structural Analysis on Car Chassis Frame}

\subsubsection{Torsional rigidity}

The torsional rigidity test was conducted for all the 3 materials for the same loading conditions and the values for Steel 304L, AA 7056-T6 and T300/Composite are around $451 \mathrm{KNm} /$ degree, $94 \mathrm{KNm} /$ degree and $22 \mathrm{KNm} /$ degree respectively. The values of torsional stiffness are within the required standard range for passenger vehicles and the design is therefore suitable. 
The value for Steel 304L is high and is considered unsuitable for use as its mass is also very high at $949.704 \mathrm{~kg}$ while a weight reduction of $61.26 \%$ and $82.4 \%$ For AA 7075-T6 and

T300 Composite is shown respectively. This weight reduction significantly helps in making the power consumption of the car more efficient thereby improving the overall performance of the car. The vertical displacement for the torsional force of $3508.3 \mathrm{~N}$ is found to be $0.0243 \mathrm{~mm}$, $0.177 \mathrm{~mm}$ and $0.498 \mathrm{mmfor}$ Steel 304L, AA7056-T6 and T300 Fibre respectively.

Although the value of deformation produced in Steel 304L is low when compared with the other 2 materials, the overall performance of the vehicle will be affected substantially due to its high overall mass, increasing the load on the electric battery demanding more power to be used as compared to the AA 7075-T6 and T300 Composite. The results are tabulated in TABLE III.

\subsubsection{Frontal Impact Test}

The frontal impact test is done to verify if the chassis design is suitable for use in the situation of a high impact on the chassis frame taking into consideration the passenger safety. The equivalent von-Mises stress generated on impact has to be lesser than the ultimate tensile strength of the material to be suitable and safe to use. The equivalent von-Mises stress for $20 \mathrm{KN}$ force is found to be $62.297 \mathrm{MPa}, 63.288 \mathrm{MPa}$ and 59.388MPa for Steel 304L, AA 7056-T6 and T300 Composite respectively as seen in Fig IX, Fig X and Error! Reference source not found.

The Finite element analysis was conducted to ensure that the materials were within their safe stress limits. It is inferred from the results as the stress-induced in all the new material chassis frames did not exceed their respective ultimate tensile strength thereby making the design safe. The results for frontal impact are tabulated in

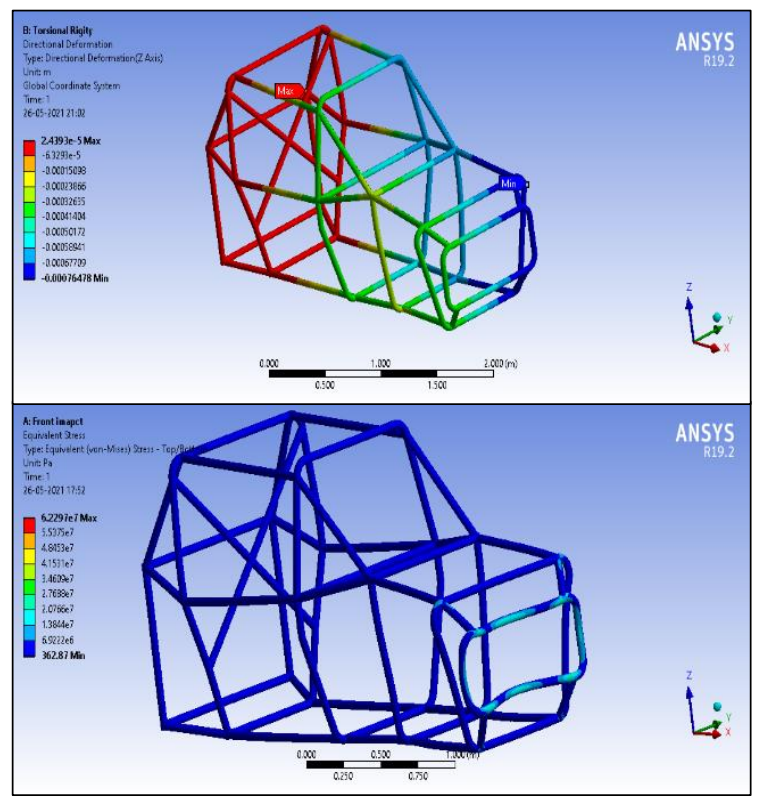

Fig IX. Torsional Rigidity and Frontal Impact on Chassis Frame for Steel $304 \mathrm{~L}$

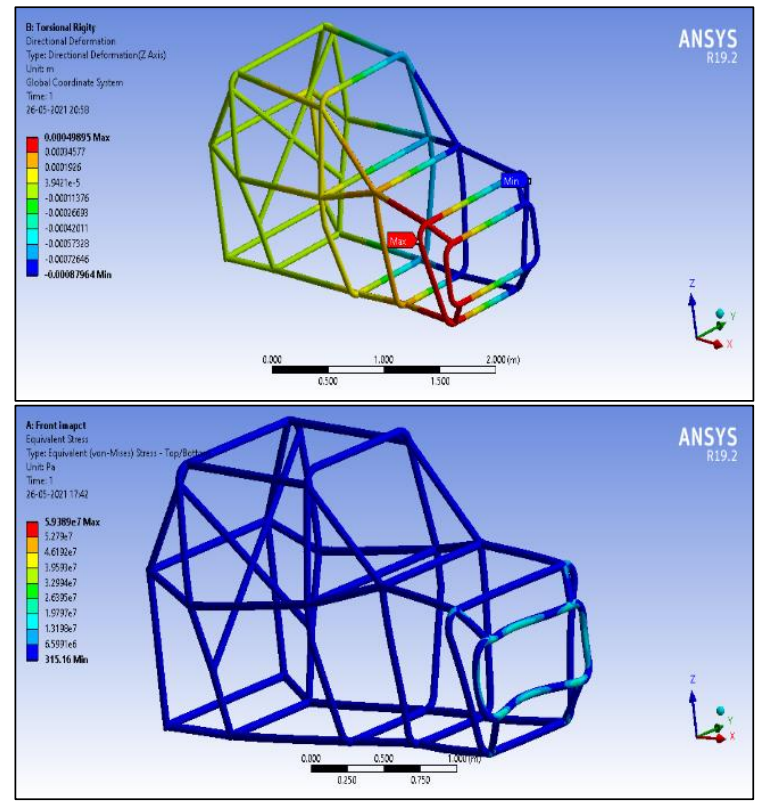

Fig X. Torsional Rigidity and Frontal Impact on Chassis Frame for AA 7075

TABLE VI

\begin{tabular}{llll}
\hline Material & $\begin{array}{l}\text { Force } \\
(\mathrm{kN})\end{array}$ & $\begin{array}{l}\text { Total } \\
\text { deformation } \\
(\mathrm{mm})\end{array}$ & $\begin{array}{l}\text { Equivalent von- } \\
\text { Mises stress }(\mathrm{MPa})\end{array}$ \\
\hline Steel & 10 & 0.139 & 31.148 \\
304L & 20 & 0.279 & 62.297 \\
& & & 31.644 \\
AA & 10 & 0.376 & 63.288 \\
7075 & 20 & 0.753 & \\
& & & 29.695 \\
T300 & 10 & 0.465 & 59.388 \\
\hline
\end{tabular}


NET WEIGHT REDUCTION

\begin{tabular}{lll}
\hline Material & $\begin{array}{l}\text { Weight of chassis } \\
(\mathrm{kg})\end{array}$ & $\begin{array}{l}\text { Net Weight } \\
\text { Reduction }(\%)\end{array}$ \\
\hline Steel 304L & 949.704 & N/A \\
AA 7056 & 367.847 & 61.46 \\
T300/Epoxy & 166.877 & 82.4 \\
\hline
\end{tabular}

Fig XI. Torsional Rigidity and Frontal Impact on Chassis Frame for T300 Composite

TABLE VII

POWER LOAD ON DIFFERENT CHASSIS MATERIALS

\begin{tabular}{llll}
\hline $\begin{array}{l}\text { Chassis } \\
\text { Material }\end{array}$ & $\begin{array}{l}\text { Speed } \\
(\mathrm{kmph})\end{array}$ & $\begin{array}{l}\text { Power Load on } \\
\text { Battery }(\mathrm{kW})\end{array}$ & $\begin{array}{l}\text { Net Reduction } \\
\text { of Load }(\%)\end{array}$ \\
\hline Steel 304L & 60 & 3.25 & N/A \\
AA 7075-T6 & 60 & 1.83 & 43.69 \\
T300/Epoxy & 60 & 1.34 & 58.76 \\
\hline
\end{tabular}

\section{CONCLUSIONS}

This study aimed to design a chassis and body for an electric Car vehicle to accommodate 2 persons providing a suitable and efficient aerodynamic design and adequate stability and passenger safety with suitable torsional rigidity and structural strength, which has been successfully done as inferred from the results.

1. The Drag coefficient of the designed electric car body ranges from 0.3482 to 0.3460 for inlet velocity speed ranging from $40 \mathrm{kmph}$ to $80 \mathrm{kmph}$, and is therefore suitable for use. The range of a standard small passenger vehicle is required to be within the range of 0.2- 0.4
2. The total weight of the chassis is found to be maximum with Steel 304L materials yielding $949.704 \mathrm{~kg}$ to the lowest weight being $166.877 \mathrm{~kg}$ for T300 Composite.

3. The heavy weight of the Steel 304L material makes it inappropriate for use as chassis material, as its high mass increases the power load on the battery making it inefficient and below the required standards.

4. The chassis made from AA 7075-T6 shows a net weight reduction of $61.46 \%$ along with $\mathrm{T} 300$ Composite showing a weight reduction of $82.4 \%$ when compared

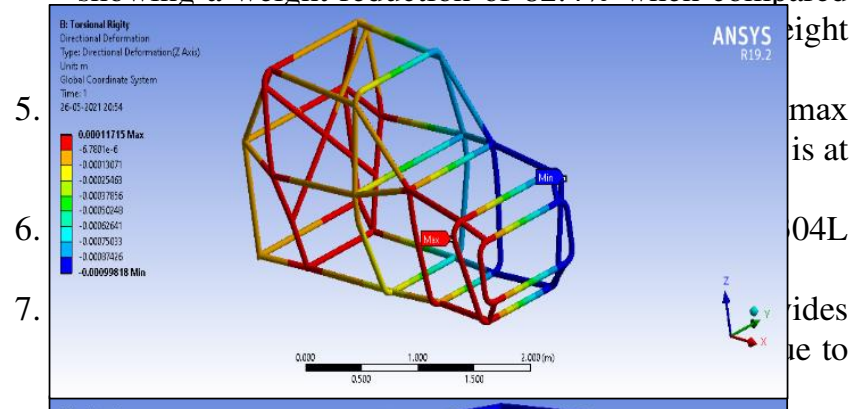

8.

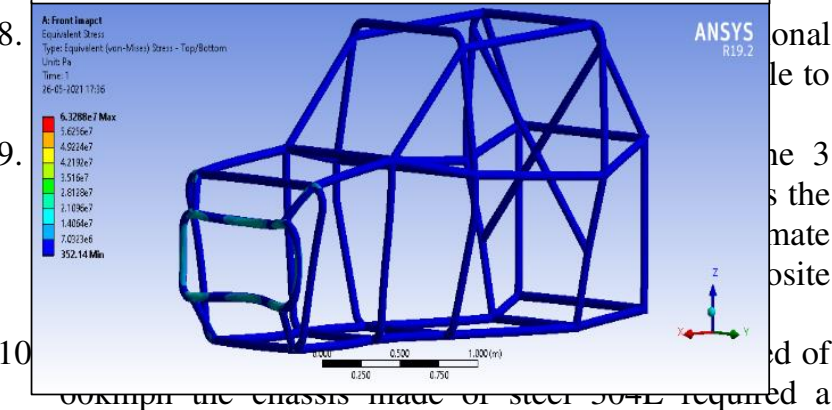

$3.25 \mathrm{KW}$ of power to run while that of AA 7075-T6 and T300 Composite required $43.69 \%$ and $58.76 \%$ less for the same conditions. (TABLE VII)

11. Weight optimization of the chassis by changing materials was successfully performed by implementation of structural analysis.

\section{REPLICATION OF RESULTS}

The optimisation, design and simulation results in this article have been performed using the CATIA V5 software and ANSYS 19.2 software packages which are available to public and widely used for research and design works. All information on inputs on design and simulation data has been explained in the manuscript. The information on material properties have been derived from (www.toraycma.com) for T300 composite material and that of Aluminium alloy and steel 304L have been derived from similar sources after verification from multiple such sources. Positive results for all analysis were obtained. Theoretical calculations were used to verify torsional stiffness of the chassis. (Luiz CarlosGertz, 2015)

\section{REFERENCES}


1. Evangelos Ch. Tsirogiannis, G. E. (2019). Electric Car Chassis for Shell Eco Marathon:Design, Modelling and Finite Element. World Electric Vehicle Journal.

2. Georgios Koumartzakis, P. S. (2018). design and development of protype electric vehicle chassis. 7th BETA CAE International Conference.

3. H Ahmad, A. A. (2020). A review of carbon fiber materials in automotive industry. IOP Conf. Series: Materials Science and Engineering.

4. Hc, A. (1993). Chassis Engineering.

5. Louis Cattafesta, C. B. (2010). Fundamentals of WindTunnel Design. Encyclopedia of Aerospace Engineering,.

6. Luiz CarlosGertz, A. C. (2015). Chassis Design for Electric Car Prototype. SAE Brazil.

7. R.K. Kawade, M. N. (2017). Chassis Frame Torsional Stiffness Analysis. International Journal for Scientific Research \& Development.

8. Steven Tebby, E. E. (2011). Methods to Determine Torsion Stiffness in an Automotive Chassis. ComputerAided Design \& Applications, PACE (1).

9. Tamer Nabil*, A.-B. H. (2020). Experimental Approach and CFD Simulation of Battery Vehicle. International Journal of Fluid Mechanics \& Thermal Sciences. 